\title{
VALIDITY OF LOCAL POSITIONING SYSTEMS TO MEASURE EXTERNAL LOAD IN SPORTS SETTINGS: A BRIEF REVIEW
}

review paper

( ) University School of Physical Education in Wroclaw

DOI: https://doi.org/10.5114/hm.2020.94200

\section{DANIELE CONTE}

Institute of Sport Science and Innovations, Lithuanian Sports University, Kaunas, Lithuania

\begin{abstract}
The aim of this study was to review the validity of the commonly adopted local positioning systems (LPSs) in sports settings for measuring athletes' external load (i.e. distances, speeds, accelerations, and decelerations), with a special focus on systems using radio-frequency identification (RFID) and ultra-wideband (UWB) technology. The reviewed articles showed that the validity of 6 LPSs including both RFID and UWB technologies was assessed by documenting acceptable validity for measuring distances ( $<3.5 \%$ difference) when compared with reference systems across different activities and sports (indoor and outdoor). Inconsistent results have been presented for average speeds, with difference from reference systems of up to $35 \%$. Additionally, high differences have been revealed for accelerations (up to 12\%) and decelerations (up to 84\%) during movements including changes of directions and for high-intensity speeds (up to $43 \%$ difference) during small-sided games. Finally, the reviewed studies suggest a higher validity in measuring instant speeds and accelerations in LPSs compared with other tracking systems (global positioning systems and video-based systems). In conclusion, this review paper implies acceptable validity of the investigated LPSs in measuring distances, while caution should be observed when measuring speeds, accelerations, and decelerations. Moreover, this review provides sports coaches, practitioners, and club directors with valuable information on purchasing and using LPSs in sports settings.
\end{abstract}

Key words: ultra-wideband, radio-frequency identification, construct validity, Catapult, WIMU PRO

\section{Introduction}

Monitoring workload during game and training in team sports is fundamental to training prescription, injury prevention, and optimizing the rehabilitation process [1]. Workload has been classified as external and internal load [1]. Specifically, external load indicates the training stimulus imposed, while the internal load represents the physiological reaction of the athlete resulting from the imposed stimulus [1]. Typical measures of external load in team sports are total distance covered in different speed zones and the number of sprints, accelerations, and decelerations. Therefore, the adoption of sound monitoring systems able to accurately quantify the position and locomotion of team sports athletes is fundamental to having a precise measure of the athletes' external load.

In the last two decades, tracking devices have been extensively used in several sports owing to techno- logical advancements [2, 3]. One of the most applied tracking technologies is the Global Positioning System (GPS), a satellite-based navigation technology, originally devised for military purposes [2]. This technology requires GPS satellites orbiting the Earth and sending time information to the GPS receivers at the speed of light to determine the receivers' position trigonometrically [3]. GPS has been extensively used in team sports, with an increased number of research studies published in the last few years [3] documenting acceptable reliability and validity to measure locomotion in team sports athletes [4]. However, the main limitation of the GPS technology is its restriction to outdoor facilities and thus to outdoor team sports (i.e. rugby, football, Australian football, etc.). To overcome this limitation, different technologies have been developed for indoor sports settings to quantify athletes' external load. For instance, most commercially available GPS devices are integrated with micro inertial

Correspondence address: Daniele Conte, Institute of Sport Science and Innovations, Lithuanian Sports University, Sporto g. 6, Kaunas, Lithuania, 44221, e-mail: daniele.conte@lsu.lt

Received: November 19, 2019

Accepted for publication: March 4, 2020

Citation: Conte D. Validity of local positioning systems to measure external load in sports settings: a brief review. Hum Mov. 2020;21(4):30-36; doi: https://doi.org/10.5114/hm.2020.94200. 
sensors such as triaxial accelerometers, magnetometers, and gyroscopes, which do not require a satellite connection and therefore are suitable for indoor sports. These sensors, also defined as inertial measurement units (IMUs), sample at high frequency (typically $100 \mathrm{~Hz}$ ) and provide accelerometer-derived load measures, with the most common being PlayerLoad ${ }^{\mathrm{TM}}$, developed by Catapult Sports [5]. PlayerLoad ${ }^{\mathrm{TM}}$ is calculated as the square root of the sum of squared instantaneous rates of change in acceleration in the $\mathrm{x}, \mathrm{y}$, and $\mathrm{z}$ axes divided by 100 and is measured in arbitrary units [5]. The accelerometer-derived measures have been largely used in indoor sports [6-9] and showed acceptable validity and reliability $[5,10]$. However, IMUs provide only partial information about players' external load, such as inertial movement analysis of jumps, acceleration, decelerations, while other important measures, such as speeds and distances, are not estimated. Therefore, different tracking technologies have been developed and applied in indoor team sports.

\section{Local positioning systems in sports settings}

Local positioning systems (LPSs) constitute an emerging tracking technology in sports settings. An LPS determines the position of an object in the physical space continuously and in real-time and combines several technologies varying in terms of validity, costs, precision, construction, scalability, robustness, and security [11]. Beside image-based technologies (also called optical methods), which use computer vision systems designed with algorithms capable of measuring the positions of players and then derive external load measures such as distance, velocity, and acceleration [12], the radio-frequency identification (RFID) and ultrawideband (UWB) are the most emerging technologies adopted in sports settings. RFID uses radio waves to transmit the identity of an object (or person) wirelessly on the basis of exchanging frequencies of radio signal between readers (anchor nodes) and tags (mobile nodes worn by athletes) $[11,13,14]$. This technology applies proximity as the main principle to detect position and operates on a bandwidth up to $930 \mathrm{MHz}$ [11, 13]. UWB is defined as a radio-frequency signal having a fractional bandwidth greater than $20 \%$ of the centre carrier frequency, or has a bandwidth greater than $500 \mathrm{MHz}[11,13]$. UWB is a communication channel that spreads information out over a wide portion of the frequency spectrum. This technology has been suggested to provide signals able to penetrate most materials and less susceptible to inferences compared with RFID [11, 13]. Assessing the UWB validity seems fundamental to providing accurate information about athletes' external load measures. It is important to develop independent research to enhance the understanding of these technologies.

\section{Ethical approval}

The conducted research is not related to either human or animal use.

\section{RFID and UWB systems validity}

\section{Definition of validity and accuracy}

The validity of a system, which represents the extent to which a measure is associated with that of other accepted systems that measure the same ability [15], is usually applied to test accuracy, which refers to the deviation of a measurement from its true value [16]. In the reviewed papers, the terms 'accuracy' and 'validity' are often used interchangeably and were assessed by comparing the external load parameters measured with LPSs with those measured with reference systems. Throughout the current review paper, the term 'validity' rather than 'accuracy' was used in order to avoid potential confusions. Additionally, it is important to note that validity levels were considered acceptable or not acceptable on the basis of the conclusions of the reviewed manuscripts. Therefore, no threshold values were employed since each manuscript adopted several statistical approaches to assess the validity of systems. The methodological approaches and main results concerning the reviewed RFID and UWB systems are displayed in Table 1.

\section{Radio-frequency identification}

The first study assessing the validity of a RFID system was performed in an outdoor environment (i.e. football pitch) [17]. Specifically, the distances and speeds measured with the Inmotio Object Tracking BV system (Amsterdam, the Netherlands) were compared with those measured with reference systems (measuring tape and timing gates) during soccer-specific drills, including linear and change-of-direction (COD) paths. The results indicated an acceptable validity owing to mean difference in distances $<1.6 \%$ and high relationships ( $r$ of 0.71-0.97) and small differences (1.3-3.9\%) for average speeds across the various paths.

Successively, the validity of the Wireless Ad hoc System for Positioning (WASP), which operates in the 


\section{HUMAN MOVEMENT}

D. Conte, Validity of local positioning systems

Table 1. Methodological approaches and main results of the reviewed articles

\begin{tabular}{|c|c|c|c|c|c|c|c|c|}
\hline Authors & Manufacturer & Technology & $\begin{array}{l}\text { External } \\
\text { load } \\
\text { measures }\end{array}$ & Participants & Facility & Sport/activity & $\begin{array}{l}\text { Reference } \\
\text { system }\end{array}$ & Main results \\
\hline $\begin{array}{l}\text { Frencken } \\
\text { et al. } \\
{[17]}\end{array}$ & Inmotio & RFID & $\begin{array}{l}\text { Distance } \\
\text { and speed }\end{array}$ & 3 males & $\begin{array}{l}\text { Football } \\
\text { (soccer) } \\
\text { pitch }\end{array}$ & $\begin{array}{l}4 \text { soccer-specific } \\
\text { courses, } 10 \text { times } \\
\text { each }\end{array}$ & $\begin{array}{l}\text { Measuring } \\
\text { tape and } \\
\text { timing gates }\end{array}$ & $\begin{array}{l}\text { Mean difference in distance } \\
<1.6 \% ; 1.3-3.9 \% \text { for average speeds }\end{array}$ \\
\hline $\begin{array}{l}\text { Ogris } \\
\text { et al. } \\
{[19]}\end{array}$ & $\begin{array}{l}\text { Local } \\
\text { Positioning } \\
\text { Measure - } \\
\text { Abatec }\end{array}$ & RFID & Velocity & $\begin{array}{l}6 \text { amateur } \\
\text { soccer players }\end{array}$ & $\begin{array}{l}\text { Football } \\
\text { (soccer) } \\
\text { pitch }\end{array}$ & $\begin{array}{l}\text { Small-sided games } \\
\text { and } 276 \text { runs on } \\
3 \text { different courses } \\
\text { at } 6 \text { different speeds }\end{array}$ & $\begin{array}{l}\text { Camera- } \\
\text {-based } \\
\text { motion } \\
\text { system }\end{array}$ & $\begin{array}{l}\text { Mean difference of } 0.01-0.23 \mathrm{~km} \cdot \mathrm{h}^{-1} \\
\text { for velocities }\end{array}$ \\
\hline $\begin{array}{l}\text { Sathyan } \\
\text { et al. } \\
{[18]}\end{array}$ & $\begin{array}{l}\text { Wireless Ad } \\
\text { hoc System } \\
\text { for Positioning } \\
\text { (WASP) }\end{array}$ & RFID & Distances & $\begin{array}{l}10 \text { elite-level } \\
\text { athletes ( } 6 \text { male } \\
\text { and } 4 \text { female) }\end{array}$ & $\begin{array}{l}\text { Indoor } \\
\text { (basketball } \\
\text { court) and } \\
\text { outdoor } \\
\text { (rugby pitch) }\end{array}$ & $\begin{array}{l}\text { Walk, jog, run, } \\
\text { and sprint on linear } \\
\text { and non-linear paths } \\
\text { (total of } 160 \\
\text { measures) }\end{array}$ & $\begin{array}{l}\text { Ruler attached } \\
\text { to the upper } \\
\text { back of each } \\
\text { participant }\end{array}$ & $\begin{array}{c}\text { Mean errors of distance } \\
\text { of } 2.2-2.7 \% \text { and } 1.3-3.2 \% \\
\text { in indoor and outdoor, } \\
\text { respectively }\end{array}$ \\
\hline $\begin{array}{l}\text { Leser } \\
\text { et al. } \\
{[20]}\end{array}$ & Ubisense & UWB & Distance & $\begin{array}{l}13 \text { male basketball } \\
\text { players }\end{array}$ & $\begin{array}{l}\text { Basketball } \\
\text { court }\end{array}$ & $\begin{array}{l}\text { Two practice } \\
\text { basketball matches }\end{array}$ & Trundle wheel & Difference of $3.45 \%$ for distances \\
\hline $\begin{array}{l}\text { Rhodes } \\
\text { et al. } \\
\text { [21] }\end{array}$ & Ubisense & UWB & $\begin{array}{l}\text { Distance, } \\
\text { mean and } \\
\text { peak speed }\end{array}$ & $\begin{array}{l}2 \text { physically active } \\
\text { males with } \\
\text { experience in } \\
\text { rugby wheelchair } \\
\text { propulsion }\end{array}$ & $\begin{array}{l}\text { Wheelchair } \\
\text { basketball } \\
\text { and ruby court }\end{array}$ & $\begin{array}{l}\text { Wheelchair-sport- } \\
\text { specific test }\end{array}$ & $\begin{array}{l}\text { Laser total } \\
\text { station } \\
\text { and wireless } \\
\text { timing gates }\end{array}$ & $\begin{array}{l}\text { Difference for distances, mean speed, } \\
\text { and peak speeds }<2.0 \%\end{array}$ \\
\hline $\begin{array}{l}\text { Serpiello } \\
\text { et al. } \\
\text { [13] }\end{array}$ & $\begin{array}{l}\text { ClearSky T6 } \\
\text { Catapult }\end{array}$ & UWB & $\begin{array}{l}\text { Distance, } \\
\text { speed, } \\
\text { acceleration, } \\
\text { and decele- } \\
\text { ration }\end{array}$ & $\begin{array}{l}6 \text { recreationally } \\
\text { active men }\end{array}$ & $\begin{array}{l}\text { Basketball } \\
\text { court }\end{array}$ & $\begin{array}{l}10 \text { repetitions } \\
\text { of } 4 \text { different } \\
\text { locomotor activities } \\
\text { (walking, jogging, } \\
\text { maximal acceleration, } \\
\text { 45-degree change } \\
\text { of direction) }\end{array}$ & $\begin{array}{l}\text { Camera-based } \\
\text { motion system }\end{array}$ & $\begin{array}{l}\text { Mean difference in distance, mean } \\
\text { and peak speeds, mean and peak } \\
\text { acceleration: } 0.2-12 \% \text {; mean and } \\
\text { peak decelerations difference: } 21- \\
84 \% \text {; moderate-to-large difference } \\
\text { when considering change-of-direction } \\
\text { movements }\end{array}$ \\
\hline $\begin{array}{l}\text { Luteberget } \\
\text { et al. } \\
{[14]}\end{array}$ & $\begin{array}{l}\text { ClearSky T6 } \\
\text { Catapult }\end{array}$ & UWB & $\begin{array}{l}\text { Distance } \\
\text { and } \\
\text { instanta- } \\
\text { neous } \\
\text { speeds }\end{array}$ & $\begin{array}{l}2 \text { male and } \\
2 \text { female active } \\
\text { handball } \\
\text { athletes }\end{array}$ & $\begin{array}{c}\text { Indoor sport } \\
\text { hall measuring } \\
(50 \times 70 \times 11 \mathrm{~m})\end{array}$ & $\begin{array}{l}5 \text { tasks imitating } \\
\text { team sports } \\
\text { movements }\end{array}$ & $\begin{array}{l}\text { Infra-red } \\
\text { camera } \\
\text { system }\end{array}$ & $\begin{array}{c}\text { Difference for distance }<2 \% \text {; } \\
\text { difference for instantaneous } \\
\text { speed }>33 \%\end{array}$ \\
\hline $\begin{array}{l}\text { Bastida- } \\
\text { Castillo } \\
\text { et al. [22] }\end{array}$ & WIMU PRO & UWB & $\begin{array}{l}\text { Distance } \\
\text { on } \mathrm{x} \text { and } \mathrm{y} \\
\text { axes } \\
\text { (raw data) }\end{array}$ & $\begin{array}{l}4 \text { healthy well- } \\
\text { trained males }\end{array}$ & $\begin{array}{l}\text { Basketball } \\
\text { court }\end{array}$ & $\begin{array}{l}\text { Participants running } \\
\text { on perimeter of the } \\
\text { court, middle line } \\
\text { of the court, exterior } \\
\text { perimeter of the } \\
\text { painted lines, centre } \\
\text { circle, } 6.75-\mathrm{m} \text { line }\end{array}$ & $\begin{array}{c}\text { Geographic } \\
\text { information } \\
\text { system }\end{array}$ & Difference ca. $1 \%$ on both axes \\
\hline $\begin{array}{l}\text { Linke } \\
\text { et al. } \\
\text { [23] }\end{array}$ & $\begin{array}{l}\text { Inmotio/ } \\
\text { GPSports/ } \\
\text { STATS }\end{array}$ & $\begin{array}{l}\text { RFID/GPS/ } \\
\text { Video- } \\
\text {-based }\end{array}$ & $\begin{array}{l}\text { Distance, } \\
\text { instant } \\
\text { speed and } \\
\text { acceleration, } \\
\text { distances at } \\
\text { different } \\
\text { speed and } \\
\text { acceleration } \\
\text { thresholds }\end{array}$ & $\begin{array}{l}14 \text { male U19 } \\
\text { football } \\
\text { (soccer) } \\
\text { players }\end{array}$ & $\begin{array}{l}\text { Football } \\
\text { (soccer) } \\
\text { pitch }\end{array}$ & $\begin{array}{l}\text { Sport-specific course, } \\
\text { shuttle runs, and } \\
\text { small-sided games }\end{array}$ & $\begin{array}{l}\text { Camera-based } \\
\text { motion system }\end{array}$ & $\begin{array}{l}\text { LPS and GPS documented } \\
\text { the best validity compared } \\
\text { with video technology in instant } \\
\text { speeds (LPS: } 0.25 \pm 0.06 \mathrm{~m} \cdot \mathrm{s}^{-1} \text {, } \\
\text { GPS: } 0.25 \pm 0.06 \mathrm{~m} \cdot \mathrm{s}^{-1} \text {, video tech- } \\
\text { nology: } 0.41 \pm 0.08 \mathrm{~m} \cdot \mathrm{s}^{-1} \text { ) and } \\
\text { accelerations (LPS: } 0.68 \pm 0.14 \mathrm{~m} \cdot \mathrm{s}^{-2} \text {, } \\
\text { GPS: } 0.67 \pm 0.21 \mathrm{~m} \cdot \mathrm{s}^{-2} \text {, video } \\
\text { technology: } 0.91 \pm 0.19 \mathrm{~m} \cdot \mathrm{s}^{-2} \text { ). } \\
\text { Poor validity in high-speed actions } \\
\text { during small-sided games for each } \\
\text { system (errors: LPS: } 43 \%, \text { GPS: } 97 \% \text {, } \\
\text { video technology: } 98 \% \text { ) }\end{array}$ \\
\hline $\begin{array}{l}\text { Bastida } \\
\text { Castillo } \\
\text { et al. [24] }\end{array}$ & WIMU PRO & UWB/GPS & $\begin{array}{l}\text { Average } \\
\text { speeds and } \\
\text { distance }\end{array}$ & $\begin{array}{l}10 \text { healthy } \\
\text { well-trained } \\
\text { former football } \\
\text { (soccer) players }\end{array}$ & $\begin{array}{l}\text { Football } \\
\text { (soccer) } \\
\text { pitch }\end{array}$ & $\begin{array}{c}\text { Linear course, } \\
\text { circle course, } \\
\text { and zig-zag course }\end{array}$ & Timing gates & $\begin{array}{l}\text { UWB lower bias compared with GPS } \\
\text { in distance covered (UWB: } 0.57- \\
5.85 \% \text {, GPS: } 0.69-6.05 \% \text { ) and total } \\
\text { mean speed (UWB: from }-0.56 \\
\text { to } 0.67 \text {, GPS: from }-0.18 \text { to } 1.31 \text { ) }\end{array}$ \\
\hline
\end{tabular}

UWB - ultra-wideband, RFID - radio-frequency identification, GPS - Global Positioning System, LPS - local positioning system 
5.8-GHz industrial, scientific, and medical band and uses 125-MHz bandwidth, was assessed in both indoor (basketball courts) and outdoor (rugby pitch) settings by using 12 anchor nodes [18]. Validity was assessed by measuring the relative position between two tags fixed to a ruler attached to the upper back of each participant during static (15 WASP nodes in both indoor and outdoor playing areas) and dynamic (linear and non-linear paths) measures, with results revealing an absolute positioning error of $12.1 \mathrm{~cm}$ and $11.9 \mathrm{~cm}$ for outdoor and indoor, respectively. Additionally, on the linear paths, the mean errors of the distance estimates were $2.2 \%$ and $1.3 \%$ for indoor and outdoor, respectively, while for the non-linear paths, the errors were $2.7 \%$ and $3.2 \%$, respectively.

The validity of a radio-frequency-based $(45.5 \mathrm{~Hz}$ per transponder) tracking system (LPM, Abatec, Austria; version: lpm04.59) was assessed by comparing the calculated positional data with those recorded by using an infrared-camera-based motion capture system (Vicon, Oxford, UK), adopted as reference system [19]. Both LPS base stations and the Vicon cameras were positioned around a football pitch and recorded 276 runs on 3 different courses at 6 different speeds and 10 small-sided games, with results demonstrating an average absolute error of less than $5 \%$ (i.e. $23.4 \pm 20.7 \mathrm{~cm}$ ) for positioning, and a lower error $\left(0.01-0.23 \mathrm{~km} \cdot \mathrm{h}^{-1}\right)$ for velocities compared with maximum speed estimation, which differed by up to $2.71 \mathrm{~km} \cdot \mathrm{h}^{-1}$ (mean relative difference of $10 \%$ ). The authors acknowledged an acceptable validity of this system in football although it showed increased errors when measuring instantaneous speeds.

\section{Ultra-wideband}

UWB is a relatively new technology and its validity has been recently assessed. The first system receiving attention from the scientific community was the Ubisense system, with 2 studies having investigated its validity [20, 21]. In a previous investigation, the validity of the Ubisense system (with an overall bandwidth of $137 \mathrm{~Hz}$ ) was assessed by placing receiving tags on a rugby wheelchair and measuring the distances covered and mean speeds during incremental fixed speeds movements (measured with speedometers mounted on the wheelchairs) and multidirectional movements [21]. A laser total station (Leica TS30, Leica Geosystems, UK) and wireless timing gates (Brower Timing Systems, Draper, USA) were used as criterion measurements for distances and mean speed, respectively. Additionally, the validity of the system for peak speed was evaluated during a $20-\mathrm{m}$ linear speed wheelchair test by using a wireless inertial sensor attached to the right axle of the wheelchair as a reference system. The results revealed that the Ubisense system possessed an acceptable validity for court-based wheelchair sports, with relative errors to the criterion systems of $<2.0 \%$ for distances, mean speed, and peak speeds in each investigated movement. Similarly, Leser et al. [20] indicated an acceptable validity of this system, with a mean distance travelled difference of $14.70 \pm 9.29 \mathrm{~m}$, corresponding to $3.45 \pm 1.99 \%$ when comparing it with the distance recorded by using a trundle wheel (as reference system) during a running protocol simulating basketball-specific movements. Overall, the Ubisense system showed acceptable validity in court-based team sports and wheelchair sports; however, some limitations should be acknowledged, such as the adoption of receiving tags mounted on the top of the head in team sports athletes [21], while more recent UWB systems usually locate receiving tags in manufacturer-supplied neoprene vests to secure their attachment between the scapulae, which seems a likely more appropriate site to increase the athletes' comfort.

One of the recent UWB systems adopting this location and being used in indoor court-based team sports is the ClearSky T6 system (Catapult Sports, Australia). Its validity has been assessed in two recent studies $[13,14]$. Serpiello et al. [13] investigated the validity of this UWB system during linear and 45-degree COD running drills in an indoor court, comparing the distances, speeds, accelerations, and decelerations measured with the Catapult ClearSky T6 system and a 12-camera Vicon motion analysis system (Vicon Nexus T40, Vicon Motion Systems, Oxford Metrics, UK), used as a criterion system. The results revealed trivial-to-moderate mean differences in all investigated variables in linear locomotor activities except for mean deceleration. Specifically, the mean difference between the systems in total distance, mean and peak speed, and mean and peak accelerations ranged between 0.2 and $12 \%$, with typical errors (calculated as within-subject standard deviations and free of device error) of $1.2-9.3 \%$. When considering decelerations, high differences between the systems were shown in mean and peak decelerations ( $84 \%$ and $21 \%$, respectively). The authors of the investigation suggested that this UWB system had an overall acceptable validity compared with the Vicon system to assess linear locomotor movement. Conversely, when considering COD runs, moderate-to-large differences were found between the two systems in COD activities measured in the middle of the court, and large-to-very-large for 
COD activities in the side of the court. Additionally, Luteberget et al. [14] assessed the validity of this UWB system when performing tasks simulating team-sportsspecific movements, including several CODs, comparing the results with an infra-red camera system (Qualisys Oqus, Qualisys AB, Sweden) as a reference system. The study compared the raw two-dimensional position data for both systems, showing acceptable average difference in distance $(<2 \%)$ for all tasks when the UWB system was mounted in the optimal condition, while instantaneous speeds presented non-valid differences (> 33\%), with higher speed resulting in higher difference. Therefore, further data filtering techniques were suggested in order to optimize this discrepancy between the examined UWB system and the reference system. Moreover, the study indicated that the placement of anchor nodes largely influenced the validity of the LPS, with higher average distance and instantaneous speed differences (ca. 30\% and $>74 \%$, respectively) with a non-optimal anchor node setting.

The most recently studied UWB system is the WIMU $\mathrm{PRO}^{\mathrm{TM}}$ (Realtrack Systems, Almeria, Spain). Its validity was assessed by using a geographic information system mapping software, which allows representation of geometrical shapes, such as polygons or circles, with millimetre validity as a reference system [22]. In the study protocol, raw positional data on the $\mathrm{x}$ and $\mathrm{y}$ axes were compared and the results showed a betweensystem difference of $<1 \%$ on both axes, documenting an acceptable validity.

\section{Validity and comparison with}

other tracking devices

The validity of the LPS Inmotio system (Inmotio Object Tracking BV, Amsterdam, the Netherlands) was also compared with that of other commonly used tracking devices, such as semi-automatic multiple camera video technology (STATS SportVU) and GPS technology (GPSports, Sports Performance Indicator Pro X, Canberra, Australia) [23]. An infrared camera-based motion capture system (Vicon, Oxford, UK) was used to assess the validity for each tracking device in estimating instant speeds and accelerations, distances, and distances run at different speed and acceleration thresholds during sport-specific courses, shuttle runs, and small-sided games played on an outdoor football pitch. The LPS and GPS technologies documented the best validity compared with the video technology, with statistically lower differences compared with the reference system in measuring instant speeds (LPS: $0.25 \pm 0.06 \mathrm{~m} \cdot \mathrm{s}^{-1}$, GPS: $0.25 \pm 0.06 \mathrm{~m} \cdot \mathrm{s}^{-1}$, video technology: $0.41 \pm 0.08 \mathrm{~m} \cdot \mathrm{s}^{-1}$ ) and accelerations (LPS: $0.68 \pm 0.14 \mathrm{~m} \cdot \mathrm{s}^{-2}$, GPS: $0.67 \pm 0.21 \mathrm{~m} \cdot \mathrm{s}^{-2}$, video technology: $0.91 \pm 0.19 \mathrm{~m} \cdot \mathrm{s}^{-2}$ ). When considering total distance, all systems showed acceptable validity, with percentages of root mean square error from the reference system ranging from $2.18 \%$ to $3.95 \%$. Regarding distances travelled at different speed thresholds, acceptable validity was shown for all systems at low and moderate intensity, while all systems reported non-valid results for high speed distances during small-sided games, with high difference in the percentages of root mean square error from the reference system (LPS: 43\%, GPS: 97.4\%, video technology: 97.6\%).

In a similar validity study including the comparison with other tracking technologies, the validity of the WIMU PRO system in measuring speed and distances in outdoor setting (football pitch) was assessed [24]. Specifically, the distances and speeds measured with the WIMU PRO system and a GPS device during linear, circular, and zig-zag courses were compared with those provided by timing gates as a reference system. The results revealed a better validity of the UWB system compared with the GPS system, with a lower bias compared with the reference system in distance covered (UWB: 0.57-5.85\%, GPS: 0.69-6.05\%) and in total mean velocity measurements (UWB: from -0.56 to 0.67 , GPS: from -0.18 to 1.31 ). Furthermore, the UWB technology showed a statistically lower bias compared with the GPS technology in velocities while sprinting across the circular and zigzag paths, as well as in distances when walking on a circular path and when sprinting on a linear path.

\section{Discussion and practical considerations}

The technological advancement of the RFID and UWB systems has led to an increased number of commercially available LPSs in sports settings. The systems reviewed in this manuscript documented acceptable validity in measuring mainly distances (differences with reference systems < 3.5\%) [13, 14, 17, 18, 20-24] and in some cases speeds and accelerations [19, 21, $23,24]$, while other commercially available systems did not report any scientific evidence of their validity. It is suggested for sports clubs to carefully check the validity level of the LPSs when purchasing and using them in measuring external load parameters. Specifically, it is advised to direct the purchase to validated systems and avoid those not showing scientific evidence of validity in measuring external load parameters. It is also recommended to use the most recently reviewed UWB systems since they represent an advanced tech- 
nology compared with RFID systems $[11,13]$ and indicate acceptable validity in measuring some of the external load parameters during sport-specific movements $[13,14,22]$.

Another important consideration for team sports practitioners is the identification of the most important and sport-specific external load measures, which could provide appropriate information about the entire training process and the quantification of the match physical demand. The reviewed papers assessing the validity of different LPSs showed acceptable validity in measuring distances [13,14, 17, 18, 20-24], which is probably not the most representative external load parameter, in particular in court-based team sports, mainly characterized by high-speed activity, accelerations, and decelerations. In the context of these external load measures, little information has been provided for the reviewed LPSs, with only a few studies indicating low validity levels during high-speed actions, accelerations, and decelerations when performing team-sportspecific movements, including CODs and small-sided games $[13,14,23]$. These results imply the necessity to interpret the external load measures assessed with this system with caution; possibly, coaches and practitioners should integrate this information with IMUs, usually embedded within the LPS receiving tags, which showed acceptable validity and reliability [10], in order to obtain a clearer picture of athletes' external load.

The validity of the reviewed LPSs has been shown mainly in indoor sports settings, while these systems have a potential to be used also in outdoor settings. Only a few studies investigated the validity of the RFID and UWB systems in a football (soccer) pitch, indicating an acceptable validity [20, 23, 24]. Furthermore, the comparison with other tracking devices commonly used outdoors, such as video-based and GPS technology, showed a better validity of LPSs in measuring mainly distances [23, 24]; when considering high intensity speed actions and accelerations during game-based conditioning drills, none of the investigated technology reported an acceptable validity, which suggests the use of these external load measures with caution [23]. Additionally, bearing in mind the different results obtained when comparing different technologies, one should suggest not to use different tracking systems interchangeably [23]. Although all the reported RFID and UWB systems showed acceptable validity, it should be noted that different reference systems were used across the studies, making direct comparisons impossible.

Future studies should focus on analysing the validity of LPSs in estimating speeds, distances at various speeds, accelerations, and decelerations across several indoor and outdoor sports. Additionally, while the validity of the reviewed RFID and UWB systems has been reported, only a few studies concentrated on investigating the reliability of these systems [17, 21, 24]. Therefore, further research should explore the reliability of the LPSs using known measures for distances, speeds, accelerations, and decelerations. Moreover, while most of the studies focused on analysing some linear or sport-specific singular movements $[13,14$, $17,18,21,22,24]$, limited information is available about the validity of the systems during actual matches or game-based drills, such as small-sided games, in different sports, which calls for further studies in this area. Finally, the current review analysed only the RFID and UWB systems, which are currently the most used LPSs in team sports, while other technologies are emerging in sports settings, such as the wireless local area network (WLAN) [25] and Bluetooth [26]. These technologies also showed encouraging results in terms of validity when measuring external load parameters $[25,26]$. Future investigations should focus on the comparison of different LPS technologies in assessing external load parameters.

\section{Conclusions}

In conclusion, this review paper suggests the validity of the reviewed LPSs in measuring distances, while caution should be observed when measuring speeds, accelerations, and decelerations. Additionally, the review might provide sports coaches, practitioners, and club directors with valuable information on purchasing and using LPSs in sports settings.

\section{Disclosure statement}

The author does not have any financial interest and did not receive any financial benefit from this research.

\section{Conflict of interest}

The author states no conflict of interest.

\section{References}

1. Impellizzeri FM, Marcora SM, Coutts AJ. Internal and external training load: 15 years on. Int J Sports Physiol Perform. 2019;14(2):270-273; doi: 10.1123/ ijspp.2018-0935.

2. Cummins C, Orr R, O’Connor H, West C. Global positioning systems (GPS) and microtechnology sensors in team sports: a systematic review. Sports Med. 2013; 43(10):1025-1042; doi: 10.1007/s40279-013-0069-2.

3. Malone JJ, Lovell R, Varley MC, Coutts AJ. Unpacking the black box: applications and considerations for 
using GPS devices in sport. Int J Sports Physiol Perform. 2017;12(Suppl. 2):S218-S226; doi: 10.1123/ ijspp.2016-0236.

4. Cardinale M, Varley MC. Wearable training-monitoring technology: applications, challenges, and opportunities. Int J Sports Physiol Perform. 2017;12(Suppl. 2):S255-S262; doi: 10.1123/ijspp.2016-0423.

5. Boyd LJ, Ball K, Aughey RJ. The reliability of minimaxX accelerometers for measuring physical activity in Australian football. Int J Sports Physiol Perform. 2011;6(3):311-321; doi: 10.1123/ijspp.6.3.311.

6. Kniubaite A, Skarbalius A, Clemente FM, Conte D. Quantification of external and internal match loads in elite female team handball. Biol Sport. 2019;36(4):311316; doi: 10.5114/BIOLSPORT.2019.88753.

7. Sansone P, Tessitore A, Paulauskas H, Lukonaitiene I, Tschan H, Pliauga V, et al. Physical and physiological demands and hormonal responses in basketball smallsided games with different tactical tasks and training regimes. J Sci Med Sport. 2019;22(5):602-606; doi: 10.1016/j.jsams.2018.11.017.

8. Schelling X, Torres L. Accelerometer load profiles for basketball-specific drills in elite players. J Sports Sci Med. 2016;15(4):585-591.

9. Fox JL, Scanlan AT, Stanton R. A review of player monitoring approaches in basketball: current trends and future directions. J Strength Cond Res. 2017;31(7): 2021-2029; doi: 10.1519/JSC.0000000000001964.

10. Nicolella DP, Torres-Ronda L, Saylor KJ, Schelling X. Validity and reliability of an accelerometer-based player tracking device. PLoS One. 2018;13(2):e0191823; doi: 10.1371/journal.pone.0191823.

11. Alarifi A, Al-Salman A, Alsaleh M, Alnafessah A, AlHadhrami S, Al-Ammar MA, et al. Ultra wideband indoor positioning technologies: analysis and recent advances. Sensors. 2016;16(5):707; doi: 10.3390/s16050707.

12. Sampaio J, McGarry T, Calleja-González J, Sáiz SJ, Schelling i del Alcázar X, Balciunas X. Exploring game performance in the National Basketball Association using player tracking data. PLoS One. 2015;10(7): 132894; doi: 10.1371/journal.pone.0132894.

13. Serpiello FR, Hopkins WG, Barnes S, Tavrou J, Duthie GM, Aughey RJ, et al. Validity of an ultra-wideband local positioning system to measure locomotion in indoor sports. J Sports Sci. 2018;36(15):1727-1733; doi: 10.1080/02640414.2017.1411867.

14. Luteberget LS, Spencer M, Gilgien M. Validity of the Catapult ClearSky T6 local positioning system for team sports specific drills, in indoor conditions. Front Physiol. 2018;9:115; doi: 10.3389/fphys.2018.00115.

15. Currell K, Jeukendrup AE. Validity, reliability and sensitivity of measures of sporting performance. Sports Med. 2008;38(4):297-316; doi: 10.2165/00007256200838040-00003.

16. Ranstam J. Methodological note: accuracy, precision, and validity. Acta Radiol. 2008;49(1):105-106; doi: 10.1080/02841850701772706.
17. Frencken WGP, Lemmink KAPM, Delleman NJ. Soccer-specific accuracy and validity of the local position measurement (LPM) system. J Sci Med Sport. 2010; 13(6):641-645; doi: 10.1016/j.jsams.2010.04.003.

18. Sathyan T, Shuttleworth R, Hedley M, Davids K. Validity and reliability of a radio positioning system for tracking athletes in indoor and outdoor team sports. Behav Res Methods. 2012;44(4):1108-1114; doi: 10.3758/s13428-012-0192-2.

19. Ogris G, Leser R, Horsak B, Kornfeind P, Heller M, Baca A. Accuracy of the LPM tracking system considering dynamic position changes. J Sports Sci. 2012;30(14): 1503-1511; doi: 10.1080/02640414.2012.712712.

20. Leser R, Schleindlhuber A, Lyons K, Baca A. Accuracy of an UWB-based position tracking system used for time-motion analyses in game sports. Eur J Sport Sci. 2014;14(7):635-642; doi: 10.1080/17461391.2014. 884167.

21. Rhodes J, Mason B, Perrat B, Smith M, Goosey-Tolfrey V. The validity and reliability of a novel indoor player tracking system for use within wheelchair court sports. J Sports Sci. 2014;32(17):1639-1647; doi: 10.1080/ 02640414.2014 .910608 .

22. Bastida-Castillo A, Gómez-Carmona CD, De la CruzSánchez E, Reche-Royo X, Ibáñez SJ, Pino Ortega J. Accuracy and inter-unit reliability of ultra-wide-band tracking system in indoor exercise. Appl Sci. 2019;9:939; doi: 10.3390/app9050939.

23. Linke D, Link D, Lames M. Validation of electronic performance and tracking systems EPTS under field conditions. PLoS One. 2018;13(7):e0199519; doi: 10.1371/journal.pone.0199519.

24. Bastida Castillo A, Gómez Carmona CD, De la Cruz Sánchez E, Pino Ortega J. Accuracy, intra- and inter-unit reliability, and comparison between GPS and UWBbased position-tracking systems used for time-motion analyses in soccer. Eur J Sport Sci. 2018;18(4):450-457; doi: 10.1080/17461391.2018.1427796.

25. Hoppe MW, Baumgart C, Polglaze T, Freiwald J. Validity and reliability of GPS and LPS for measuring distances covered and sprint mechanical properties in team sports. PLoS One. 2018;13(2):e0192708; doi: 10.1371/journal.pone.0192708.

26. Figueira B, Gonçalves B, Folgado H, Masiulis N, Calleja-González J, Sampaio J. Accuracy of a basketball indoor tracking system based on standard Bluetooth low energy channels (NBN23 ${ }^{\circledR}$ ). Sensors. 2018;18(6): 1940; doi: 10.3390/s18061940. 